\title{
Do Events Have Their Parts Essentially?
}

\author{
ABSTRACT: \\ We argue that mereological essentialism for events is independent of mereological essentialism \\ for objects, and that the philosophical fallout of embracing mereological essentialism for \\ events is minimal. We first outline what we should consider to be the parts of events, and then \\ highlight why one would naturally be inclined to think that the object-question and the \\ eventquestion \\ are linked. Then we argue that they are not. We also diagnose why this is the case, \\ and emphasize the upshot. In particular, we argue that the way we evaluate modal claims \\ which concern events differs from the way we evaluate modal claims which concern objects. \\ Ultimately, then, to our title question we say: the answer doesn't matter as much as you might \\ think. \\ KEYWORDS: \\ Events, Mereology, Mereological Essentialism, Modality \\ WORD COUNT (TOTAL): \\ 4,545 \\ AUTHORS: \\ Paul R. Daniels (Monash University) \& Dana Goswick (University of Melbourne) \\ paul.daniels@gmail.com dgoswick@unimelb.edu.au
}

Consider the object, Prince William, and the event, Prince William's bachelor party. There are a variety of questions we can ask about each: could Prince William have nine toes instead of ten? Could he be taller than he actually is, or be a leopard instead of a man? Could Prince William's bachelor party involve different people? Could it be a birthday party instead of a bachelor party? There are clear parallels between the questions raised here with respect to the object, Prince William, and those raised with respect to the event, Prince William's bachelor party. In particular, all these questions are mereological in nature and ask if the salient entity could be different than it actually is. For instance, Prince William's having nine toes instead of ten seems to require a mereological change- the loss of a part (i.e. a toe). Likewise, his bachelor party having different guests requires a mereological change-the loss of some parts and the addition of others (e.g. people). ${ }^{1}$ Despite these parallels, we argue below that the question of mereological essentialism for events is independent from the question of mereological essentialism for objects. Our diagnosis of why this is the case also reveals a key difference in the way we evaluate modal claims which concern events and objects. Furthermore, we argue that this reveals why the answer to our title question doesn't matter as much as one might think.

\footnotetext{
${ }^{1}$ Could we just paraphrase away talk of objects as event-parts? That is, for instance, could we talk about Prince William as merely the subject of his bachelor party instead of as part of the party? We might be tempted to so as this would, at a minimum, have the advantage of making the problem we're interested in here hard to articulate. But it's crucial that we don't rush to an under-motivated position, even if it seems to some intuitive or natural. After all, the metaphysics of events has garnered a great deal of attention in the literature. And we might reasonably ask: do our well-developed theories of events entail that objects are parts of events? (As we explain below, the answer will be in the affirmative for many of the prominent theories of events.) We revisit a more substantive version of this question in $\$ 1$.
} 
Do events have parts? It would be too hasty to take it to be a priori obvious that events don't have parts. After all, Quine (1960) equates objects and events, and endorses the classical mereological claim that objects have parts. It follows from these two claims that events have parts—at least according to a Quinean about events. Even those who accept the more intuitive view that events and objects are distinct ontological categories can claim that events have parts. Lewis (1986), for instance, argues that events are sets, and that sets have parts. It follows from these claims that events have parts. Fine (2010) differs from Quine (in that he takes events to be distinct from objects) and differs from both Lewis and Quine (in that he's a pluralist, rather than a monist, about the parthood relation). However, he too claims that events have parts. Given the wide-range of philosophers that take events to have parts and the wide-range of differing philosophical views which are compatible with events having parts, we think it is not a priori obvious that events lack parts. So, what are the parts of events? And do they have those parts essentially? These are the questions we're concerned with here.

And, prima facie, one might think that if mereological essentialism is false for objects, then it's false for events. After all, some equate objects and events-e.g. Reichenbach (1947) and Quine (1960)—while others take them to be very closely connected (identity or partial constitution). Moreover, if object and event are just two terms which pick out the same ontological category, then the falsity of mereological essentialism for objects (MEO, hereafter) seems to guarantee the falsity of mereological essentialism for events (MEE, hereafter). Alternatively, if events have objects as parts, then, given the transitivity of parthood, events have the parts of objects as parts. Thus, if the objects which are parts of events have accidental parts (i.e. if MEO is false), surely events will have accidental parts as well (i.e. MEE will be false). But despite the prima facie plausibility of such claims, the case against MEE— even given the falsity of MEO—is far from clear. Consequently, we think it's worth exploring exactly what events parts are and whether they're had essentially or accidentally.

To that end, in $\$ 1$, we further strengthen the view that they are linked and, in the process, we clarify what we should consider to be the parts of events. Then, in $₫ 2$, we attack the view that they are linked and argue that the truth of MEE is independent of the truth of MEO. But we ultimately neither endorse nor reject MEE. We think there are plausible accounts of events which embrace MEE and plausible ones which reject it. Our goal here isn't to adjudicate between them. Our goal, rather, is to illustrate how the question of MEE differs importantly from the question of MEO. This difference sheds light on how we think about objects and events. We argue that MEE can be true, even if MEO is false, because the way in which we evaluate modal claims concerning events differs from the way we evaluate modal claims concerning objects. ${ }^{2}$

${ }^{2}$ We might think this problem of MEE is particular pressing for those who follow Fine (2010). Fine sketches a very general framework of part-whole, in which mereology is merely a small branch. This approach to mereology is noteworthy here as Fine is explicitly interested in extending the notion of a part beyond its application to material objects. In Fine's view, there is a plurality of kinds of mereological relations and hybrid parts. That said: even for those who reject Fine's more generalized theory, and instead accept a more 
1. If asked, most of us can easily list parts of a dog (e.g. head, eyes, atoms). What about if asked to list the parts of an event? This may stump some. Others, though, may point to its temporal parts (e.g. Lombard 1995, Allen 2005). We might think this a plausible answer as temporal parts are what we colloquially focus on when we talk about events. After all, if asked "which part of the party did Prince William enjoy the most?" a sensical answer would surely be something like "the first part" or "the part when we played darts." Intuitively, we might think this reveals how an event is carved up into its smaller parts. And we might suspect that the parthood of events hits bedrock here as, for instance, an answer of the following sort "the biggest toe on his left foot" doesn't seem to be a sensical answer to that question. But caution is in order here as it's not the case that the mere naturalness of such remarks entail, for instance, that his toe is not a part of the event. ${ }^{3}$ So while we might intuitively want to list only the temporal parts of an event as its parts, merely doing so would ultimately be unsatisfactory as we can't rule out, a priori, that events have further non-temporal parts. This is revealed when we consider, for instance, an instantaneous temporal part of an event: at this time, what are the parts of this part of the event in question? This question is intelligible and will have a substantive answer. We can further emphasize this if we consider MEO. Just as a discussion of MEO would be unsatisfactory if it only considered the temporal parts of an objectsince objects may have additional non-temporal parts—a discussion of MEE which only considers the temporal parts of an event would be similarly unsatisfactory. ${ }^{4}$ There are clear parallels here and in order to assess the tenability of MEE, we need to know what the further parts of events are. Think of it this way: think of an event, and consider an instantaneous temporal part of it; call this temporal part, $T$. What are the proper parts of $T$ ? Since $T$ is just all of Prince William's bachelor party that exists at that time, the proper parts of $T$ are, arguably, things like all of the salient timeslices of the people attending the party. Could $T$ have had different parts than it actually does? Could, for instance, the time-slice of Prince William which is a part of $T$ have contained one less toe than it actually contains? Could $T$ have had a time-slice of an additional person (i.e. if an additional guest had attended the party)? If $T$ itself could have had different parts, then-given the transitivity of parthood-Prince William's bachelor party could have had different parts. ${ }^{5}$ Such

orthodox view of mereology, MEE prompts a serious concern. These concern principally shakes out of how we conceptualize events, as we discuss below.

${ }^{3}$ See Fine (2010) for a discussion of the plurality of parthood, as well as conceptions of parthood on which William's toe is part of the event of Prince William's bachelor party. See Lewis (1991) and Simons (1987) for discussion of whether events have such parts on a monistic conception of parthood.

${ }^{4}$ For the sake of brevity with regard to the present point, we assume perdurantism is true-i.e. the view that persisting entities are 4D space-time worms with temporal parts. This, of course, is controversial. While many accept perdurantism, others do not. Nevertheless, the veracity of perdurantism is ultimately orthogonal to our aims here. We merely invoke it as an aside here to undermine the claim that temporal parts could be the sole parts of events.

5 One way to capture a crucial issue here may be: is parthood transitive when it comes to events? Two discussions inform a robust answer here. On the one hand, mereology; one the other hand, theories of events. In mereology, parthood is standardly taken to be transitive. That said, Fine (2010) argues that some parthood relations aren't transitive. Since our focus is on events as understood by Quine, Lewis, and Kim- 
questions ask the mereological essentialist question, but we cannot appeal to further temporal parts here since $T$ has no further temporal proper parts. All this is to say that, just as an instantaneous temporal part of an object may have further parts which the mereological essentialist considers essential parts of the object, instantaneous temporal parts of an event may have further parts which the mereological essentialist considers essential parts of the event. Given this, before we can evaluate the plausibility of mereolgoical essentialism for events, we need to know if objects, regions, properties, and so on are parts of events when events are properly understood. ${ }^{6}$

Some may press this issue, though, in a different way. They may argue that while the Prince is a member of the group of people who are partying, and his toe is part of him, the Prince isn't a part of the party: the Prince may be the subject of the event, but the subject of an event, the region at which it occurs, and the properties it exemplifies are not properly understood as parts of an event. Just as, for instance, MEO isn't concerned with the spatiotemporal region at which an object exists-i.e. even the mereological essentialist allows for the possibility that the very same object could have existed over here or over there (so long as it had all the same parts, wherever it's found)-MEE isn't concerned with the spatiotemporal region at which an event occurs (or its subject, or the properties it exemplifies). The parts of an event really only are its temporal parts. So when we ask if the bachelor party could involve different people, or if it could be a birthday party instead of a bachelor party, we aren't asking the about the essentiality of the parts of the event; we're asking a different sort of essentialist question. Consequently, unless we focus our attention on the temporal parts of events, we aren't focusing on MEE. However, this presupposes a particular account of events. To take this line is to assume a particular answer to the more general question, "what is an event?" Or, at least, this line of thinking excludes answers which do include objects, properties or regions as parts of events. But it's far from established that objects aren't parts of events. In order to answer a question like “is Prince William's toe part of the party?" we need an account of events. And so, properly understood, a mereological essentialist about events will maintain that Prince William's toe is an essential part of the party-but only if objects are to be understood as parts of events.

To that end, let's consider three of the most prominent accounts of events: Quine (1985), Lewis (1986), and $\operatorname{Kim}(1969,1976)$. As we aren't interested in adjudicating between these accounts of events here, we shall consider all three. Once we've seen what the parts of events are according to each, we'll be able to evaluate whether or not MEE is true-i.e. whether the specified parts are had essentially according to each. So consider the event your walking of the dog this morning: There you are at $9 \mathrm{am}$ in the front yard, then a bit further around the block at 9:05am, then half way around the

and all three adhere to the traditional view that parthood is transitive-we follow orthodox mereology here. So, we take parthood to be transitive. In regards to events themselves, the theory of events one favours will dictate whether or not the way events are conceived of leaves room for an answer to this transitivity question that differs from the answer to it with respect to objects.

${ }^{6}$ We might further wonder if, say, properties are of a sort which could even be parts. We won't engage with this tangential question here, but notice that bundle and trope theorist will certainly insist that they can be. 
block at 9:10am, then three-quarters of the way around the block at 9:15am, then back at in the front yard at 9:20am. According to Quine (1960: 171) an event is the material content of a region of spacetime, and the parts of an event are the material contents of the subregions of the event region. So, according to the Quinean, this dog walking event is just the material content of every region in which you walk the dog. ${ }^{7}$ The proper parts of that which occupies these regions will be proper parts of the event. According to Lewis (1986: 244), events are sets which contain as members the minimal spacetime region, and that which occupies it, of each world in which the event occurs. Here the dog walking event is $\left\{\mathrm{W}_{\mathrm{ad}}, \mathrm{W}_{1 \mathrm{dd}}, \mathrm{W}_{4 \mathrm{~d}}, \mathrm{~W}_{6 \mathrm{~d}}, \mathrm{~W}_{7 \mathrm{~d}}\right\}$. $^{8}$ Since the dog's nose and your left ear are parts of $\left\{\mathrm{W}_{\mathrm{ad}}\right\}$ and $\left\{\mathrm{W}_{\mathrm{ad}}\right\}$ is a part of $\left\{\mathrm{W}_{\mathrm{ad}}, \mathrm{W}_{1 \mathrm{~d}}, \mathrm{~W}_{4 \mathrm{~d}}, \mathrm{~W}_{6 \mathrm{~d}}, \mathrm{~W}_{7 \mathrm{~d}}\right\}$, the dog's nose and your left ear are parts of the event-namely, $\left\{\mathbb{W}_{\mathrm{ad}}, \mathrm{W}_{1 \mathrm{~d}}, \mathrm{~W}_{4 \mathrm{~d}}, \mathrm{~W}_{6 \mathrm{~d}}, \mathrm{~W}_{7 \mathrm{~d}}\right\}$. According to Kim, events are ordered triples which have an object, a property, and a time as parts (Kim 1976). Here the dog walking event is $[x, F, t]$ where $x$ picks out an object (you and the dog), $F$ picks out a property (a walk by person $p$ and $\operatorname{dog} d$ ) and $t$ picks out a time (the interval of time which stretches from the beginning of the walk to the end of the walk); these are its parts, according to the Kimean. ${ }^{9}$

So, what can we say about whether or not events have their parts essentially? Each view of events adequately motivates, within the context of the view as a whole, its chosen answer to the question "What are the parts of an event?" and we must approach the question of MEE on a viewby-view basis. So how does MEE fares within each of these views? Quine (1985: 171) takes both objects and events to be mereological fusions governed by the principles of classical extensional mereology: 'Physical Objects, conceived thus four-dimensionally in spacetime, are not to be distinguished from events or, in the concrete sense of the term, processes. Each comprises simply the content, however heterogeneous, of some portion of spacetime, however disconnected and gerrymandered'. Since fusions have their parts essentially and events are fusions, events have their parts essentially. So if Quine's account of events is correct, then MEE is true. What of Lewisian events? Lewis (1986: 258) argues that if events are classes, as I propose, then they have a mereology in the way that all classes do: the parts of a class are its subclasses'. But showing that an event has its subclasses essentially won't yet show that mereological essentialism is true according to

${ }^{7}$ See Quine (1960) for more on Quine's view about what the material contents of objects/events are.

8 The first subscript after the W (i.e. a, 1, 4, 6, 7) picks out a world in which the event occurs. The second subscript after the $\mathrm{W}$ (i.e. d) picks out the minimal spacetime region of the specified world in which you walk the dog at that world. While there are five occurrences of the event, your actual dog only went on one walk this morning; the others are taken by counterparts.

${ }^{9}$ While Kim speaks of constituents rather than parts (Kim 1976: 162), here we take constituents to be parts since, in general, when philosophers speak of form and matter as constituents of an object they mean parts of the object. So it's natural to think when Kim speaks of an object, a property, and a time as constituents of an event, he means they are parts of the event. On this point, also see Kim's discussion of the inclusion-relation: the official line of his view here is that, although the event $e_{1}$ of Sebastian's stroll is not identical to the event $\mathrm{e}_{2}$ of Sebastian's leisurely stroll, there is a sense in which the second includes the first. And he notes that 'obviously, the sense in which an assassination includes a killing or strolling leisurely includes strolling is very different from the sense in which, say, my walking to the door includes my moving my left foot to take the first step and the burning of the barn includes the burning of the roof of the barn. But I assume that it's intuitively plausible to say there is some relation here that can be called "inclusion."” (Kim 1976: 170) 
the Lewisian. For mereological essentialism to be true of Lewisian events, given the transitivity of parthood, a Lewisian event must not only have its subclasses essentially but also the parts of its parts essentially (i.e. of its subclasses). Does $\mathrm{W}_{\text {ad }}$ have its parts essentially? Lewis argues that it does not. Consider the dog's left ear, which is a part of $W_{a d}$. Unfortunately, at $W_{1}$, a counterpart of the dog was bitten by another dog and lost his left ear as a result. So, there's a non-actual member of the event at which a counterpart of the dog is lacking a left ear. In virtue of this, $\mathbb{W}_{\text {ad, }}$, could lack a part it actually has. So, mereological essentialism is not true of Lewisian events. For the Kimean, the existence and identity conditions of events ensure an event will have its object, property, and time as parts essentially (Kim 1976, 160-161). ${ }^{10}$ However, nothing in Kim's account of events requires him to take the parts of an event as essential to the event. So while hair $H$ is a part the event (since hair $H$ was in fact a part of the dog throughout the walk, given that the dog is part of this event and hair $H$ is a part of the dog), hair $H$ is not an essential part of the event as-at some nearby possible world-you brush the dog before the walk instead of after. Since the identity conditions Kim gives for events don't force him to say hair $H$ is an essential part of the event, mereological essentialism is false of Kimean events.

What, then, should we make of MEE? MEE is true given the Quinean account of events, but not according to the Lewisian account nor the Kimean account. More generally: whichever theory of events you favor motivates your particular answer to our title question.

2. That said, if your intuitions pull towards MEE, or if your overarching philosophical picture has MEE as a consequence, have no fear: there's little philosophical fallout from endorsing MEE as the general philosophical impact of endorsing MEE is much less than of endorsing MEO. While MEO yields implausible modal results-e.g. if MEO were true, Prince William couldn't have a greater mass than he does and the dog couldn't lose an ear-MEE has no such implausible modal results. Why does MEE have so much less of an impact on general modal questions about events than does MEO? Here's one reason: we evaluate modal questions involving objects differently than we evaluate modal questions involving events. In particular, modal claims concerning objects are typically read de re (i.e. as involving the object itself), whereas modal claims concerning events are typically read de dicto (i.e. as involving all events which satisfy the relevant event-description).

Suppose I say to you, "Prince William could have one less finger than he actually has." You're inclined to hear this statement de re. You think it implies that that very object-the one that's Prince William-could be different than it actually is, i.e. that he could lack a part that he actually has. Suppose, instead, I say to you, "Prince William's bachelor party could have included one less guest than it actually did." You're at least as inclined to hear this statement de dicto as you are to hear it de

${ }_{10}$ Where the existence condition for event, $e$, is: $e$ exists just in case the object $x$ has the property $P$ at time $t$. And the identity condition for events $e$ and $e^{*}$ are: $e=e^{*}$ just in case $e^{\prime}$ s constituent object is identical to $e^{* \prime}$ s constituent object, $e^{\prime}$ s constituent property is identical to $e^{* \prime}$ s constituent property, and $e^{\prime}$ s constituent time is identical to $e^{* 1}$ s constituent time. 
re. That is, you might think this implies that that very event—Prince William's bachelor partycould be different than it actually is, i.e. that it could lack a part it actually has. However, you're at least as likely to think that it implies that some event which satisfied the event-description "Prince William's bachelor party" could have included one less guest. MEE has little impact on salient modal questions because-due to our focusing de dicto on the class of events which satisfy the relevant event-description rather than our focusing de re on the particular event itself-whether or not some event, $e$, has all its parts essentially has no bearing on the truth of modal claims concerning it. What matters to general modal questions concerning $e$ isn't its parts (or properties), but rather what matters are the parts (or properties) of the class of events which satisfy the relevant event-description. The relevant question is not "could that very party have been a birthday party instead of a bachelor party?" but, rather, "is there some event within the class of events that counts as Prince William's bachelor party which is a birthday party instead of a bachelor party?" Hence, MEO has a much larger impact on general modal questions because whether or not an object has all its parts essentially bears directly on the truth of modal claims concerning it—due to the de re rather than de dicto reading. When we evaluate modal questions about an object we don't shift to other objects which satisfy the same object-description; rather we consider only that object itself if we're analyzing modality via transworld identity, or only it and its counterparts if we're analyzing modality via counterpart theory. Given this, it's easy to see how the question of MEE is orthogonal to the question of MEO. The object, Prince William, has the same parts iff there's no possible world in which Prince William (or any of his counterparts) have different parts. The event Prince William's bachelor party has the same parts iff every event which satisfies the description "Prince William's bachelor party" has the same parts.

So, even supposing that MEO is true, it doesn't follow that MEE is true. That is, if Prince William has all his parts essentially, there might be an event which satisfies the description "Prince William's bachelor party" which doesn't even involve Prince William (e.g. suppose he took ill at the last moment, but his party went on without him). Since the actual event which satisfies the description "Prince William's bachelor party" does include Prince William, this would be an example of an event having a part accidentally—even though Prince William has all his parts essentially. Or suppose, alternatively, that MEO is false. Here Prince William doesn't have all his parts essentially. In this case it doesn't follow that MEE is false: Prince William might be able to survive the loss of a finger, but-if e.g. the Quinean account of events is correct-the event Prince William's bachelor party cannot survive the loss of William's finger. Worlds at which William has one less finger, are worlds at which a different—albeit highly similar-event occurs. Again, we see that the object-question and the event-question are separate. There is a clear disconnect between MEO and MEE.

To sum up: what are the parts of an event? Not merely temporal parts, we argued. What count as its parts is determined by one's preferred view of events. Consequently, when asked if events have 
their parts essentially, the answer will be dictated by one's preferred theory of events. Is this cause for concern? That is, for instance, if you favour a Quinean account of events should you lose sleep over the modal consequences of your commitment to MEE? We argued that you need not worry. There's little philosophical fallout form endorsing MEE because modal claims about events are read de dicto (rather than de re). Consequently, MEE has little impact on salient modal questions. And since there's an important disconnect between MEO and MEE, you needn't fret if you find yourself forced to embrace MEE. In short, it doesn't really matter whether or not events have their parts essentially.

\section{References}

Allen, Robert. "The mereology of events." Sorites (2005): 23-37.

Fine, Kit. "Towards a Theory of Part." The Journal of Philosophy (2010): 559-589.

Kim, Jaegwon. "Events and their descriptions: some considerations." In Essays in Honor of Carl G. Hempel, Nicholas Rescher (ed.) (Springer, 1969): 198-215.

Kim, Jaegwon. Events as property exemplifications. (Springer, 1976).

Lewis, David. Parts of Classes. (Blackwell, 1991)

Lewis, David. "Events". In Philosophical Papers Voll. II. (Oxford: OUP, 1986): 241-269.

Lombard, Lawrence. "Sooner or later." Noûs (1995): 343-359.

Quine, W.V.O. Word and Object. (Cambridge: MIT Press, 1960).

Quine, W.V.O. "Events and reification." Actions and events: Perspectives on the philosophy of Donald Davidson (1985): 162-171.

Reichenbach, Hans. Elements of Symbolic Logic. (London: Macmillan Co., 1947).

Simons, Peter. Parts: A Study in Ontology. (Oxford, 1987) 


\section{University Library}

\section{- M M I E R R A A gateway to Melbourne's research publications}

Minerva Access is the Institutional Repository of The University of Melbourne

Author/s:

Goswick, D;Daniels, P

Title:

Do Events Have Their Parts Essentially?

Date:

2017

Citation:

Goswick, D. \& Daniels, P. (2017). Do Events Have Their Parts Essentially?. Acta Analytica, 30 (3), pp.267-274. https://doi.org/10.1007/s12136-016-0311-2.

Persistent Link:

http://hdl.handle.net/11343/283137 